Nations scholarships. In many cases, students are supported by families who are not rich and who are making every kind of sacrifice to get their sons or daughters through medical school. We have students who try to make it on their own money and have to take a year off to earn money to return to school. I hope these are enough examples to eliminate the idea that we are just catering to rich students.

There is no doubt that approval by the British medical establishment, and especially the GMC, would enormously help St George's to realise its goal of becoming an international school. It would not only greatly increase our intake from the developing world, especially from Africa and Asia, but it would open up our acceptance by the most advanced hospitals in the Caribbean and promote another of our dreams - that of concentrating most of our primary clinical training in the Caribbean.

School of Medicine, Grenool

SIR,-I am glad that the story of St George's University Medical School has been told (24 July, p 276), but surely the most essential victims of this exercise are the NHS patients who are being used as teaching fodder? Grenadian students come to Britain to practise on NHS patients because there are not enough patients to go round in Grenada. I know of no NHS patient who has been asked to approve the exercise or who understands the reason for Grenadian students having to travel so far. There is no question, of course, of reciprocal arrangements being offered to British students in Grenada, and so there is no parallel with the cultural student exchanges that are a valuable part of our own students' experience.

What are NHS patients gaining, either financially or in any other way, for this unnecessary invasion of their privacy? They see little obvious benefit if anything of the measly $25^{\circ}$ o of Grenadian students' fees that accompany them to Britain. Even Mrs Thatcher would surely regard this bit of private enterprise as a very bad deal.

Southampton General Hospital,

D L MCLELLAN

SIR,-Dr Smith's article (24 July, p 276) concerning St George's University School of Medicine, Grenada, was of particular interest to me. In February this year I was a visiting professor to the medical school, and offered a course to the medical students-an introduction to gynaecology. I received my medical education at the University of Sheffield in England, and qualified MB, ChB. Subsequently, I emigrated to the USA where I did postgraduate training in obstetrics and gynaecology at the University of Chicago, and have been involved in the practice of obstetrics and gynaecology and in teaching at the Medical College of Wisconsin in Milwaukee, USA. My observations may be of interest to you.

The quality of training of the St George's students is extremely high. They are, as $\mathrm{Dr}$ Smith observed, fluent in English, extremely highly motivated, and serious about their medical studies. The results of examinations which I conducted compared very favourably with American medical students. My impression is that when these young men and women qualify and enter medical practice they will be equal to their American contemporaries.

The clinical teaching facilities, certainly on the Island of St Vincent where I resided, were primitive and inadequate for bedside teaching. The students, however, receive their clinical training in accredited hospitals, mostly in the USA and a few in the UK.

Foreign medical graduates fill a vital role, certainly in the USA where the numbers of American graduates from medical schools do not adequately cover the needs of the nation. If government cannot supply this need but the private sector can and make a profit, why object? Medical schools which graduate welltrained English-speaking doctors in whom communicative skills are paramount, should be encouraged.

Good Samaritan Medical Center,

Neville SENDER

Wisconsin 53233

\section{Paraquat ingestion with methaemoglobinaemia treated with methylene blue}

SIR,-I was interested to read the experience by $\mathrm{Dr} L \mathrm{~L} \mathrm{Ng}$ and others (15 May, p 1445) with the treatment of methaemoglobinaemia as a result of paraquat ingestion, in which they suggested that cyanosis within hours of ingestion of paraquat should lead to the suspicion of methaemoglobinaemia and treatment with methylene blue.

As the authors have suggested, I also find it difficult to attribute the signs and symptoms to methaemoglobinaemia. Specifically, the degrees of cyanosis, symptoms, and the colour of the arterial blood attributed to methaemoglobinaemia do not correlate with the methaemoglobin value of $18 \cdot 7^{\circ}$. Therefore, at first sight it is surprising that the institution of methylene blue had such a dramatic effect.

In occupationally exposed individuals the use of methylene blue for the treatment of mild to moderate methaemoglobinaemia tends to be withheld, initially, probably as a result of its paradoxic methaemoglobinaemia-generating activity, which is prominent in lysates. ${ }^{1}$ As a result it has been practice to start methylene blue only if the methaemoglobin concentration exceeds $30^{\circ}$ or if recovery is excessively slow. ${ }^{2}$ In general, patients with acquired methaemoglobinaemia tolerate concentrations of methaemoglobin up to $20 \%$ without ill effect. At levels of $20^{\circ}$ o to $50 \%$ fatigue, weakness, dyspnoea, tachycardia, headaches, and dizziness may occur. Lethargy and stupor may appear with concentrations above $55^{\circ}{ }_{0} .^{3}$

All methaemoglobin-generating chemicals have additional toxic effects, and these side effects may make profound contributions to the toxic syndrome. In fact it is doubtful if any chemical agent induces an otherwise uncomplicated methaemoglobinaemia. Therefore it is probably inappropriate and misleading to suggest that there is a lethal concentration of methaemoglobinaemia without taking account of the particular agent. ${ }^{4}$ Despite the latter consideration it is generally agreed that a reduction in the circulating titre of abnormal pigment is a desirable therapeutic goal. If the methaemoglobinaemia is contained within intact and functioning erythrocytes the methylene blue certainly evokes a dramatic response. ${ }^{5}$

In light of the interesting experience of the authors, and accepting the concentration of methaemoglobin before treatment, one wonders whether electron carriers such as methylene blue have, in addition to their anti-methaemoglobinaemia function, a therapeutic role in the treatment of the other toxic effects observed with such compounds. If, in the deactivation of the other metabolites associated with similar toxic substances, pathways such as the dormant reduced nicotinamide adenine dinucleotide phosphate system are involved then it is not unreasonable to assume that the electron carrier methylene blue would have a beneficial effect. The identification of such pathways, if they in fact exist, are matters for future toxicological research.

A YARDLEY-JONES

Wirral,

Merseyside

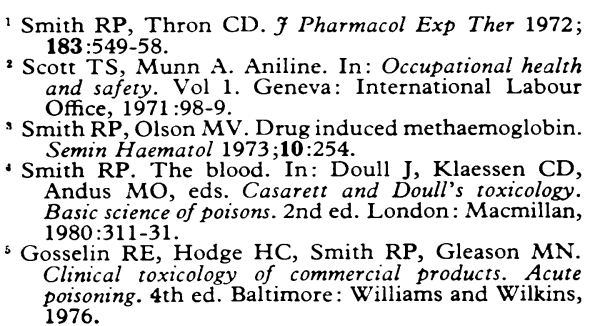

\section{Immune guided missiles}

SIR,-In the recent leading article (14 August, p 461) on the use or serotherapy it was stated that no immune response to the foreign protein in monoclonal antibodies occurs. This unfortunately is not always the case. Cosimi et al, ${ }^{1}$ using a murine anti-T cell antibody for the reversal of kidney rejection after transplantation, detected high concentrations of anti-mouse immunoglobulin antibodies, which prevented administration of further courses. Miller et $a l^{2}$ reported similar findings in a patient with $\mathrm{T}$-cell leukaemia although in their patient the effect of the anti-mouse antibody was clinically insignificant.

We have recently treated a patient with a low-grade $\mathrm{T}$-cell proliferation using a murine hybridoma monoclonal antibody which was administered on repeated occasions. ${ }^{3}$ Within 26 days the development of anti-mouse antibody, detectable at a serum dilution of $1 / 1250$, totally inhibited the effect of further serotherapy.

Small doses of aggregate-free heterologous immunoglobulin may be tolerogenic in animals, ${ }^{*}$ but this may not be the case in humans. In addition the immunosuppressive effects of the underlying disease or concurrent therapy may not be sufficient to depress the patient's humoral immune response.

Although the patients developing these anti-mouse antibodies have not suffered overt immune-complex disease, further treatment is usually prevented, and this may be a serious limiting factor in the development of mouse monoclonal antibodies for widespread use. This factor should be considered in planning treatment with these antibodies. Ideally they should be given only in short courses, or additional therapy should be given to reduce sensitisation to the foreign protein. In our patient and in the patient of Miller et al no additional chemotherapy was given and in the treatment of transplant rejection the administration of monoclonal antibody was used in some of the patients to allow reduction in the immunosuppressive agents. This may have 